\title{
INVESTIGATION OF ENERGY MANAGEMENT TOPOLOGIES FOR FORMING PRESSES WITH ELECTRO HYDROSTATIC DRIVETRAINS
}

\author{
Tim Reidl ${ }^{1 *}$, Jürgen Weber ${ }^{2}$, Steffen Ihlenfeldt ${ }^{2}$ \\ ${ }^{I}$ Moog GmbH, Hanns-Klemm-Straße 28, 71034 Böblingen \\ ${ }^{2}$ Institut für Mechatronischen Maschinenbau, Technische Universität Dresden, Helmholtzstrasse 7a, \\ 01069 Dresden \\ *Corresponding author: Tel.: +49 7031622 4844; Email address: treidl@moog.com
}

\begin{abstract}
Recent Power On Demand approaches, realized by using speed and/or displacement variable pump units, led to a significant increase of energy efficiency on hydraulic forming presses. In this paper we follow up on this development by laying the focus on the energy management and storage design of such machinery. With a derived fluidtronical model, we compare five different topologies that supply and manage the power flow for a forming press with die cushion. Our evaluation criteria are: energy consumption, minimization of the infeed power, and qualitative costs. For a representative forming cycle, the losses occurring on each of the drivetrain components and the power electronics accessory are derived in detail. We expect that this research will lead to deeper investigation of more intelligent energy management systems that use multiple storages in an optimal way and further learn and adapt during operation.
\end{abstract}

Keywords: Energy management, electro hydrostatic actuation system, peak shaving, efficiency of hydraulic forming press

\section{INTRODUCTION}

Machine manufacturers are obliged to further improve the energy efficiency of their machines due to increasing electricity costs, which most of the producing industry faces. The latest major improvement in the field of forming presses was the change from servo valve control to pump controlled displacement, as, for example, in [1] and [2]. Significant energy loss reductions are gained through the avoidance of throttle losses, as well as the re-use of temporally stored kinetic energy if the pump is operated in four quadrants. Research shows that up to $30 \%$ of energy can be saved by operating a deep drawing press with an electro hydrostatic die cushion instead of traditional hydraulics [2]. In [3], different control concepts - variable speed, variable displacement, or both simultaneously - were tested and compared regarding their efficiency. Using both control variables, speed and displacement, leads to an additional saving of up to $5 \%$ for a reference deep drawing cycle. Likewise, in [4], the author achieves up to $20 \%$ energy saving by implementing a loss-optimalcontrol strategy for a speed and displacement variable pump. The work in [5] and [6] present significant loss reduction of $40 \%$ and $30 \%$ by using an Electro Hydrostatic Actuation System (EAS) for a ring-rolling machine and a forging press. Since this technology is only in some cases cost-equivalent to valve-based control, it is crucial to lay out all components as compact and cost-effective as possible. We expect that the paradigm of "peak shaving" will play an increasingly crucial role in the field of EASbased machinery, as it does in the field of other machinery already. Peak power reduction is usually realized with a small power infeed in combination with different types of energy storages. The latter covers the peak power demands and stores energy in case of regenerative operation. The transformer, circuit breaker, mains switches and other inline elements may become significantly smaller and more cost effective if the peak power of the infeed is reduced. Furthermore, the authors in [7] point out that a predictable and rather constant load helps companies to gain "energetic flexibility" and participate in the future energy market more successfully. In countries with a 
non-negligible amount of renewable energy plants in the power supply mix, high peak loads of factories need to be compensated with fuel based power plants due to the volatile nature of e.g. wind and solar plants. Consequently, high peak power loads are "punished" by the supplier with an additional cost, according to [8].

Peak reduction approaches have been researched and implemented, for example, in the field of electromechanical servo presses. The authors of [7] and [9] analyze different storage technologies and power supply options that limit the infeed power peak. In [10] an energy management system with reduced infeed power and local electrical storage for an electromechanical punching press is presented. In this paper, we compare five different energy management topologies (EMT), by simulation, for a $1600 \mathrm{kN}$ EAS-based forming press. All studied topologies are potential solutions for handling the power flow for such a machine, each with different advantages and disadvantages. We show how much the installed power infeed can be decreased if an electric storage based on capacitors is used and how the type of topology affects the overall efficiency. Finally we will derive a rough cost indication of the investigated topologies in order to evaluate their potential in the market.

\subsection{Energy management sophistication levels}

In order to classify how advanced a certain energy management approach is we defined five levels of sophistication (SL). These are valid for EAS-based forming presses and for other machinery, where multiple axes act on the same machine or where several machines are coupled via the direct current (DC) link.

1. A common non-active front end supplies all axes. The axes exchange power over the DC bus. When the total regenerative-power is too high, it is dissipated over a bleed resistor.

2. An active front end powers all axes and feeds back current into the grid if power is regenerative. Axes exchange power over the DC bus. Infeed needs to cover peak power requirement of all axes at all times.

3. Infeed charges the passive capacitor storage and both power all axes. Regenerative power is stored in the DC bus. Infeed can be significantly downsized since peak power is provided by the capacitors.

4. Controllable storages like active capacitor units or servo flywheels are additionally coupled into the DC bus. A model-based algorithm on a controller generates command values for the infeed and the storages.

5. Like in SL 4, but the model adapts/learns on a cyclic basis and changes the available control outputs according to optimization criteria.

\section{MACHINE MODEL}

The press and cushion axis of the built model, which can be seen in Figure 1, consist of a cylinder (a), a radial piston pump (b), a permanent magnet synchronous motor (c), a DC/AC Drive (d), the power infeed (e), and an external DC bus capacity (f). The cylinders are stiffly coupled to the ram mass (g) and the cushion (h). The strong simplified model of the drawing force is represented by a damper (i) and the fluid compressibility and frame stiffness by an equivalent spring that acts between the dies (j).

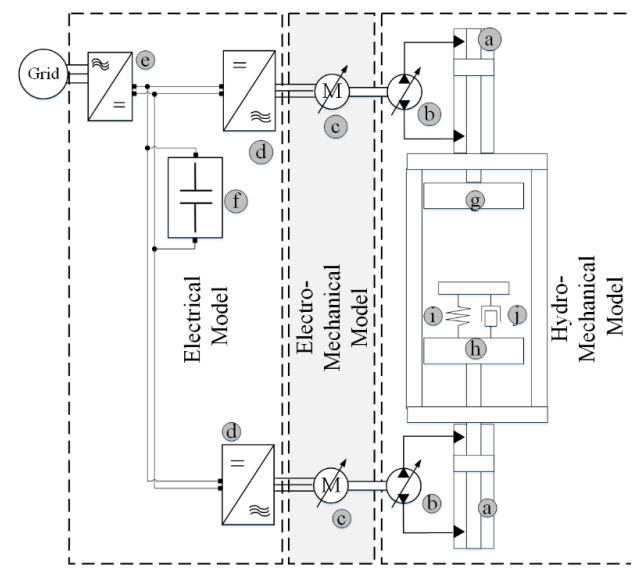

Figure 1: Schematic of the model (here with capacitor storage)

The simulation model consists of an ideal model and a loss model of each component that interact from the process backwards until the grid, as we show in Figure 3. The losses are added to the effective power flow, where then both need to be covered by the next component. The only closed loop model is the one from the infeed, as 
shown in Figure 2. It controls the DC bus voltage whereas all power flows into or out-of the DC bus act as disturbances. Since different energy management topologies are simulated, we built an infeed model that is suitable for all scenarios. Depending on the infeed type, the bus voltage and current are actively controlled; therefore the upper branch of the control scheme is active. In this case, the voltage and current controller requires tuning as well as the positive and negative current limit need to be set. In case that the infeed works passively with a bridge rectifier, the lower branch is active and, depending on actual DC bus voltage $U_{d c}$ and supply voltage $U_{\text {sup }}$, the supply current $I_{\text {sup }}$ flows in an open loop way. Both electrohydrostatic axes pull or supply power from/to the DC bus, depending on whether they accelerate, brake, press, travel, or stand. All losses from all components, including the brake choppers in case of too high voltage, dynamically take power from the bus and diminish the voltage level.

\subsection{Loss models}

The main losses that occur up to the cylinders input are:

- hydro mechanical friction and leakage loss at the pump,

- current and speed related iron loss at the motors,

- insulated-gate bipolar transistor (IGBT-) switching-, DC link- and extra-losses in the DC-AC drive,

- rectifier-, inductor-, and extra-losses for the passive infeed respectively IGBT switching losses instead for rectifier losses for the active front end,

- losses in the capacitors,

Since in this work we focus on the energy management part, mechanical friction- and fluid decompression-losses are neglected.

\section{Pump losses}

The pumps' hydromechanical friction and leakage model consist of two high dimensional lookup tables (LUT) that approximate between

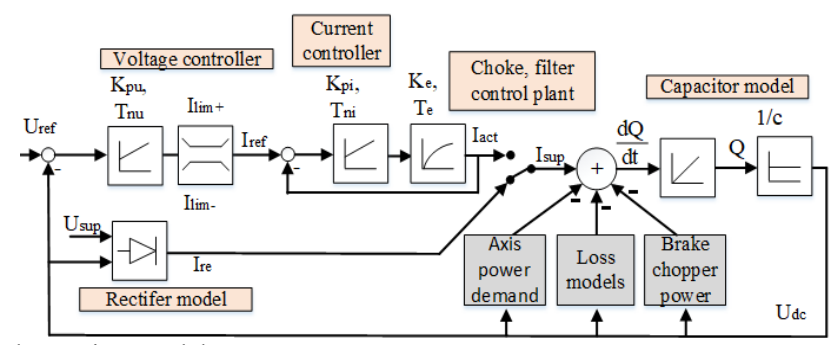

Figure 2: Ideal Infeed and capacitor model

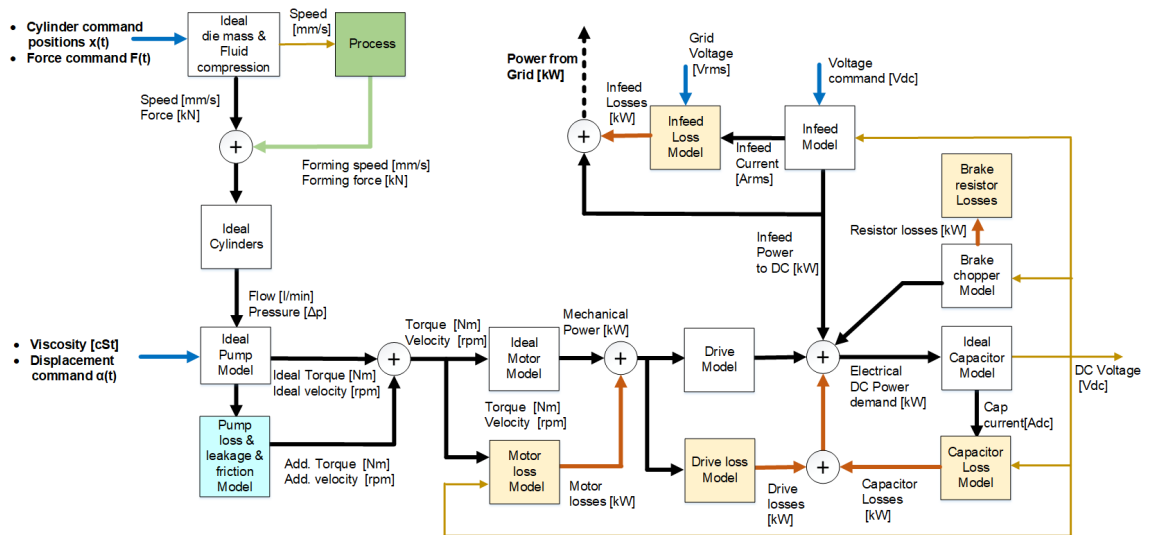

Figure 3: Architecture of the simulation model 
measured working points. The friction torque at the shaft is given out as

$\mathrm{T}_{\mathrm{fr}}=\operatorname{LUT}_{\mathrm{fr}}(\Delta \mathrm{p}, \mathrm{n}, \alpha, \mathrm{v})$,

depending on the actual motor speed $n$, pressure $\Delta p$ and displacement $\alpha$. The viscosity $\mathrm{v}$ is assumed as constant. The pumps leakage flow

$\mathrm{Q}_{1}=\operatorname{LUT}_{1}(\Delta \mathrm{p}, \mathrm{n}, \mathrm{v}, \alpha)$

is the approximated output of a second LUT with the same inputs as in equation (1). The pumps total losses are then derived as

$P_{l p}=\mathrm{Q}_{\mathrm{l}} \cdot \frac{\Delta \mathrm{p}}{600}+\frac{n \cdot 2 \cdot \pi}{60000} \cdot \mathrm{T}_{\mathrm{fr}}$.

\section{Motor losses}

As derived in [15] a permanent magnet synchronous motor consists of current dependent copper losses and iron losses. The copper losses are calculated as

$P_{c u}=3 \cdot I_{m}^{2} \cdot R_{s}$.

Whereby, the current $I_{m}$ is the root mean square value of the $\mathrm{AC}$ current in one phase and $R_{S}$ is the phase resistance of the motors' windings. The total current of a permanent magnet synchronous motor, that is operated in field oriented control, consists of the torque building $I_{q}-$ and a direct-current $I_{d}$. The total current is derived as

$I_{m}=\sqrt{I_{q}^{2}+I_{d}^{2}}$.

The amount of d-current that is needed, if the motor operates in the field weakening area, depends on the actual DC bus voltage, and so do consequently the motor losses.

Hysteresis-, Eddy current- and nonmagnetization losses can be summarized as iron losses since they all depend linearly or quadratically on the velocity of the rotating electrical field and thus of the motors speed.

$P_{f e}=f_{1} \cdot n^{2}+f_{2} \cdot n$

The constants $f_{1}$ and $f_{2}$ can be derived from thermal tests at stall and at nominal condition. The total motor losses are then

$P_{l m o t}=3 \cdot I_{m}^{2} \cdot R_{s}+f_{1} \cdot n^{2}+f_{2} \cdot n$.

\section{Drive losses}

A complete and detailed loss model of a drive is derived and verified in [11]. However, the used model requires a lot of parameters, which would go beyond the scope of this investigation. Instead we build a model that only needs the rating values from the datasheet and power consumption measurement at idle condition. Since we want to see the effect of a fluctuating bus voltage on the losses of the components, the drive model also needs to take this into consideration. The complete losses consist of the idle-operation losses $P_{l d r v 0}$ when the drive is switched on but not controlling any current. The factor $f_{3}$ can be calculated out of the nominal current and nominal voltage. The term under the square root takes the actual voltage level into consideration,

$P_{l d r v}=P_{l d r v 0}+f_{3} \cdot I_{d c} \cdot \sqrt{\frac{U_{d c}}{U_{\text {nom }}}}$

with $I_{d c}$ as the actual bus current and $U_{d c}$ the actual bus voltage. Table 1 shows the calculated losses at given rating points of current and voltage. Equation (8) estimates the losses in the range where the DC bus mainly operates. The error, comparing the calculated losses and the nominal drive losses $P_{l d r v n}$, is acceptably small.

Table 1: Ratings of the Moog Servo Drive G397 450

\begin{tabular}{llll}
\hline $\begin{array}{l}\text { Voltage } \\
{[\mathrm{Vdc}]}\end{array}$ & $\begin{array}{l}\text { Nominal } \\
\text { current } \\
\text { [Arms] }\end{array}$ & $\begin{array}{l}P_{l d r v} \\
{[\mathrm{~W}]}\end{array}$ & $\begin{array}{l}\text { Error [\%] } \\
P_{l d r v}\left(I_{d c}, U_{d c}\right) \\
-P_{l d r v n}\end{array}$ \\
\hline 565 & 450 & 5400 & 0 \\
650 & 416 & 5361 & 1 \\
678 & 405 & 5335 & 1.2 \\
\hline
\end{tabular}

\section{Active front end losses}

The active front end (AFE) losses consist of the constant part $P_{\text {lafe } 0}$, similar as in the drive model, and a current dependent part. This term inherits the nominal losses $P_{\text {nafe }}$ of the electrics and the losses $P_{l L C L}$ of the LCL filter at nominal condition and scales it linearly according to the grid current $I_{\text {grid }}$.

$P_{\text {lafe }}=P_{\text {lafe } 0}+\frac{I_{\text {grid }}}{I_{\text {nom }}} \cdot\left(P_{\text {nafe }}-P_{\text {lafe } 0}+P_{\text {lLCL }}\right)$

\section{$A C / D C / D C$ losses}

The AC/DC/DC converter rectifies without boost function and controls the current on the DC bus side. The loss model consists again of a 
constant part $P_{\text {lacdco }}$ and a term that depends linearly on the actual grid current. Since the chokes are now on the DC side, the losses $P_{n c h}$ depend on the DC current.

$$
\begin{aligned}
P_{l a c d c}= & P_{\text {lacdc0 }}+\frac{I_{\text {grid }}}{I_{\text {ninf }}} \cdot\left(P_{\text {nacdc }}-P_{\text {lacdc0 }}\right) \\
& +\frac{I_{d c}}{I_{\text {nch }}} \cdot P_{\text {nch }}
\end{aligned}
$$

\section{Capacitor losses}

A strongly simplified model of the used aluminium electrolytic capacitors basically consists of an equivalent series resistance (ESR) which induces ohmic losses when a current flows. This value depends on the dissipation factor $\tan \delta$, the capacitance $c$, and the current ripple's frequency $\omega$

$\operatorname{ESR}(\omega)=\frac{\tan \delta}{\omega C}$.

The total loss of one capacitor unit can then be derived as

$P_{l c p}=\operatorname{ESR}(\omega) \cdot I_{d c}^{2}+I_{\text {leak }} \cdot U_{d c}$,

Whereby, $I_{\text {leak }}$ is the leakage current that is characteristic for electrolytic capacitors. The dependency of the capacity and the leakage current of the actual temperature are neglected here. We assume that the ripple currents induced by the infeed's switching and the reactive power that travels between DC bus and motor are much smaller in amplitude and much higher in frequency than the active power related current. Since the losses grow quadratically with increasing current and the ESR value dilutes with increasing frequency, these small amplitude/high frequency currents are ignored. The frequency of the active power related current is set to $2 \mathrm{~Hz}$ for the ESR calculation since most of the acceleration and deceleration phases are conducted in times around 250 milliseconds.

\subsection{Model Parameters}

Table 2 shows the parameters of the hydromechanical model. Due to the high number of required parameters for the electromechanical and electrical model, we refer at this point at the datasheets of the components, listed in Table 3.
Table 2: Hydromechanical Model Parameters

\begin{tabular}{ll}
\hline Ram parameters & Value [unit] \\
\hline Cylinder area $A_{u r}$ & $510\left[\mathrm{~cm}^{2}\right]$ \\
Cylinder stroke $s_{u r}$ & $320[\mathrm{~mm}]$ \\
Ram mass $m_{u r}$ & $3500[\mathrm{~kg}]$ \\
Cushion parameters & \\
\hline Cylinder area $A_{d c}$ & $510\left[\mathrm{~cm}^{2}\right]$ \\
Cylinder stroke $s_{d c}$ & $160[\mathrm{~mm}]$ \\
Die mass $m_{d c}$ & $3500[\mathrm{~kg}]$ \\
Fluid parameters & \\
\hline Viscosity & $46[\mathrm{cSt}]$ \\
\hline Bulk Modulus & $1 \cdot 10^{4}[\mathrm{bar}]$ \\
\hline
\end{tabular}

Table 3: Datasheet parameters

\begin{tabular}{llc}
\hline Component & Product number & $\begin{array}{c}\text { Data } \\
\text { from: }\end{array}$ \\
\hline Pump unit & S-EHA 250xHOW & {$[12]$} \\
Drive & MSD G397 450 xx & {$[13]$} \\
Supply & MSD G396 026 xx & {$[13]$} \\
Capacitors & VFHR2G153YF230 & {$[14]$} \\
\hline
\end{tabular}

\section{ENERGY MANAGEMENT TOPOLOGIES}

The most cost-effective and simplest topology consists of a non-active front end (NFE) that powers the DC-AC drives and dissipates excessive occurring regenerative power over a bleed resistor. From an environmental standpoint, this is obviously not a satisfying solution. On the economic side, depending on the amount of energy that is transferred to heat, a more energy efficient solution might amortize in a decent time range (less than 2 years) and is worthwhile to consider. The press systems presented in [5] and [6]use an AFE and DC-bus coupling so that power is exchanged between the axes and in case of too much regen-power it is fed back on to the grid. However, the total maximum power that is required in the machine cycle needs to be covered by the infeed since no energy storage is present. Note that in some cases, it is not desired that any power is fed back to the factory grid. Consequently, it is mandatory to store energy or to dissipate it. 


\subsection{Simulation scenarios}

In this paper, we compare five different energy management topologies in scenarios $\mathrm{A}$ to $\mathrm{E}$, summarized in Table 4. In scenario A, B, and C the nominal power of the infeed is reduced significantly. Due to the presence of a passive energy storage device they correspond to sophistication level (SL) 3, as defined in 1.1. The topology in scenario D is able to feed back power to the grid but does not use storage, thus it belongs to SL 2. The system in scenario $\mathrm{E}$ needs to provide the maximum power needed by the axes directly from the grid and is not able to store or feed back power. Consequently it falls under SL 1.

All scenarios are simulated and sized in such a way as to cover the needed performance, whilst remaining cost effective and compact as possible. During the sizing and simulation process, we took care that none of the components' limitations were violated and that there was a reasonable margin for uncertainties. The motor's winding turns, which define the motors torque constant and thus also the drive size, are kept as high as possible by design. By doing so, the drives remain compact but the technique of field weakening is needed in order to still achieve high rotary speed.

Table 4: Energy management scenarios

\begin{tabular}{llrcl}
\hline Type & Infeed type & $\begin{array}{r}\text { Extra } \\
\text { capacity } \\
{[\mathrm{F}]}\end{array}$ & $\begin{array}{r}\text { Current } \\
\text { limit } \\
\text { [Adc] }\end{array}$ & $\begin{array}{l}\text { Bus } \\
\text { Voltage } \\
\text { [Vdc] }\end{array}$ \\
\hline A & $\begin{array}{l}\text { ACDCDC 35 } \\
\text { kVA }\end{array}$ & 0.24 & 50 & 650 \\
B & ACDCDC 35 & 0.27 & 50 & 540 \\
& kVA & & & \\
C & AFE 35 kVA & 0.24 & 50 & 700 \\
D & AFE 250 kVA & 0 & 320 & 700 \\
E & NFE 250 kVA & 0 & 400 & 540 \\
\hline
\end{tabular}

\section{Scenario $A$}

The infeed of scenario A, shown in Figure 4, rectifies the supply voltage to a DC bus voltage of $U_{d c}=1.35 \cdot U_{\text {sup }}$. Since the supply voltage was boosted by the step up transformer from 400 Vac to $480 \mathrm{Vac}$, the resulting DC bus voltage is
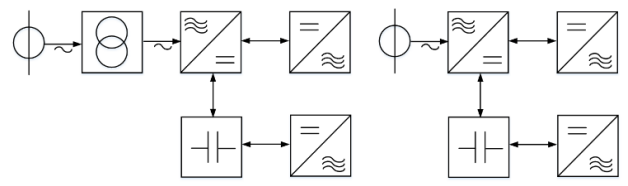

Figure 4: Topology of scenario A (left) and B (right)

$650 \mathrm{Vdc}$. This topology keeps all energy in the capacitors and is not able to feed power back to the grid.

\section{Scenario $B$}

The topology is the same as in scenario A, with the difference that the supply voltage is not transformed but directly fed in with a level of 400 Vac. The resulting DC bus voltage is thus $540 \mathrm{Vdc}$.

\section{Scenario $C$}

The AFE is supplied by 400 Vac. Due to the internal boost functionality the DC bus voltage can be elevated to $700 \mathrm{Vdc}$. The infeed is able to feed back power to the grid; however, the idea in this scenario is to keep all energy in the

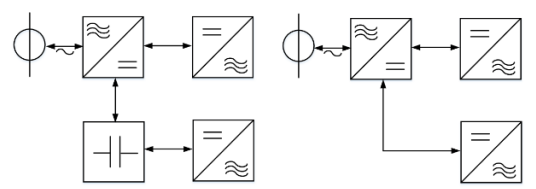

Figure 5: Topology of scenario C (left) and D (right) capacitors. Hence, the regen current limit is set to zero. The lower limit where the AFE works in a controlled way is the rectifying voltage of 540 Vdc. The topology can be seen in Figure 5. 

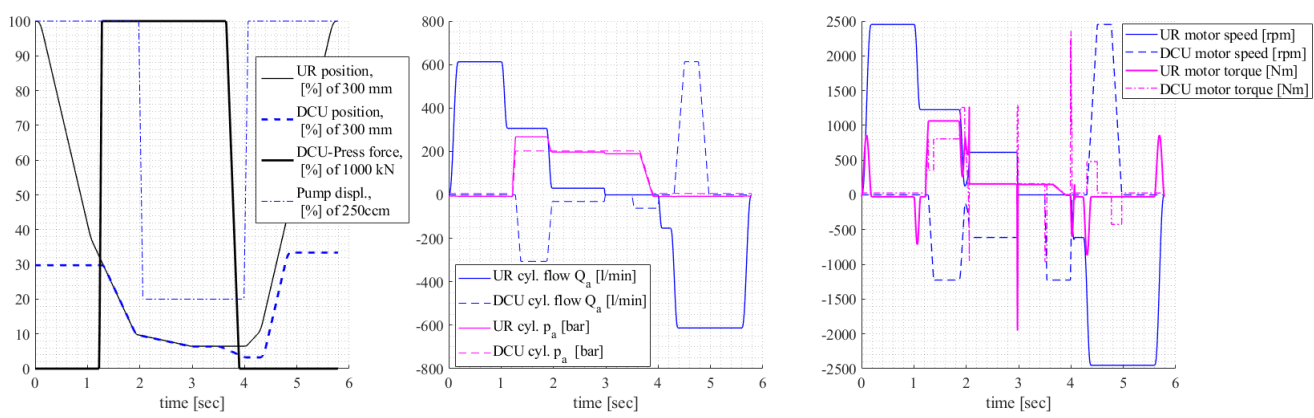

Figure 6: Upper Ram (UR) and die cushion (DCU) movement, press force and pump displacement (left). Flow and pressure at both cylinders (middle). Motors resulting speed and torque profiles (right)

\section{Scenario $D$}

The AFE covers the maximum needed power of all axes. In case that one or both axes run in regenerative mode, the power is fed back to the factory grid. The nominal DC- bus voltage is $700 \mathrm{Vdc}$.

\section{Scenario $E$}

The non-active infeed rectifies the 400 Vac supply voltage to $540 \mathrm{Vdc}$. The complete power demand needs to be covered by the power supply. In case of regenerative power inflow to the DC bus and a rise of the voltage to more than $850 \mathrm{Vdc}$, the brake chopper starts shorting the brake resistor. Consequently, part of the regen-power dissipates as heat until the voltage drops back down.

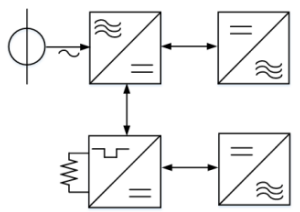

Figure 7: Topology of scenario E

\subsection{Sizing and simulation methodology}

During the sizing process, a special focus needs to be laid on the motor's torque and speed characteristic under a fluctuating bus voltage. If the voltage drops too much, the required torque at a certain speed might not be feasible, or it results in a high field weakening current which induces additional losses in the motor and drive. The graph in Figure 8 shows the duty cycle of the upper ram axis in a voltage-torque-speed phase diagram. The maps show the maximum achievable torque with and without field weakening under a varying bus voltage. The diagram shows that the required torque is not limited at any time by the motors maximum torque. However, there are phases of high speed where field weakening is necessary. The used sizing and simulation methodology respects those dynamic limits at all times and also takes the field weakening current into consideration in the overall loss balance.

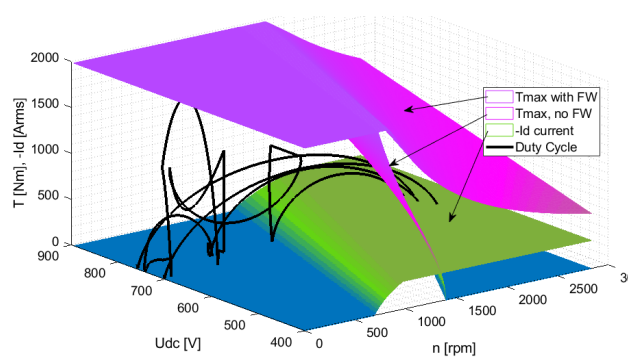

Figure 8: Duty cycle and maximum torque envelopes with and without field weakening $(\mathrm{FW})$

\section{SIMULATION AND RESULTS}

The reference duty cycle is shown in Figure 6 (left). After the ram starts moving down, the die cushion contacts with it and two different drawing velocities are realized. In order to reduce the motors' torque, the pump displacement is decreased to $20 \%$ during the low speed pressing phase. The resulting flow and pressure at the cylinders A-site are shown in the graph in the middle. The difference in pressure of the two axes is provoked by the forming force which works, together with die cushion force, against the upper die. Looking at the motors 

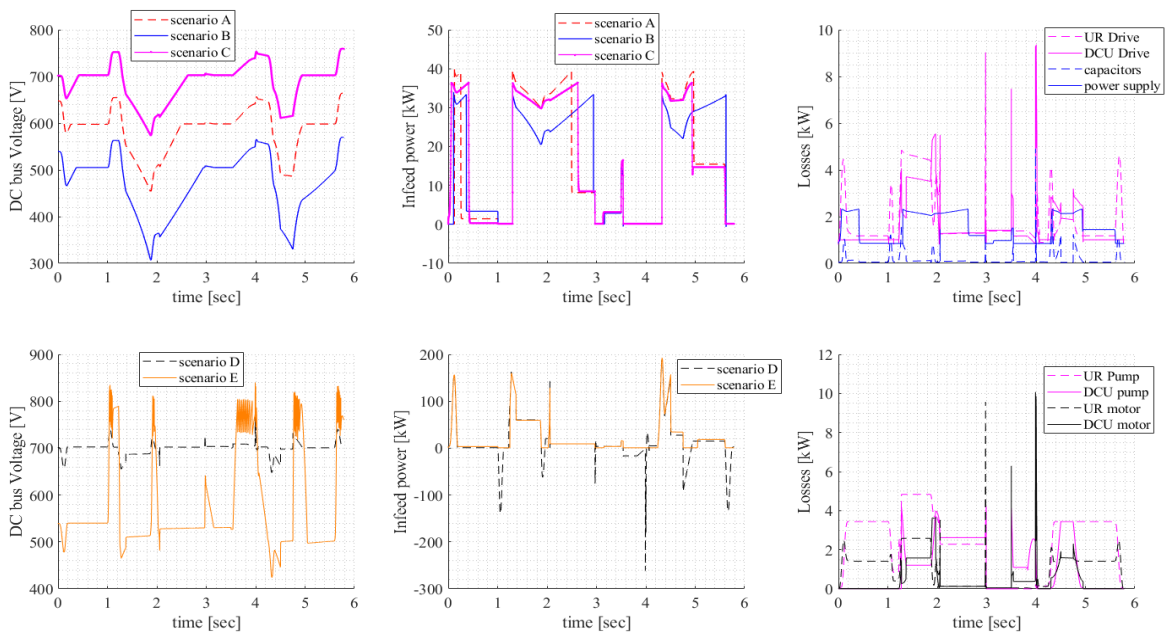

Figure 9: DC-bus voltages for all scenarios (upper left, lower left), Infeed power of all scenarios (upper middle, lower middle), Loss for all components exemplary from scenario C (upper right, lower right).

torque (right graph) we can see that during the acceleration and decceleartion phases relatively high torque peaks occur in order to speed up the motors and pump inertia. The resulting power peaks in these phases are shown in Figure 10.

During the pressing process, the DCU axes runs regenerative and part of the energy that the UR axes requires for pressing and moving down, is recuperated. The effective power demand of the axes and the losses in the pumps are always the same in all scenarios. The losses of the motors, as well as all components connected to the DC bus, are voltage dependent and consequently vary in each scenario. Looking at the DC bus voltage for the different scenarios in Figure 9 we can see that most of the energy is needed during the pressing phase and during the backwards movement of both axes, thus the voltage level decays the most during these stages. For the scenarios with lower DC reference voltage this decay is much more drastic, since with limited current inflow, the incoming power diminishes due to the voltage drop. In scenario $\mathrm{E}$, the voltage rises five times over $800 \mathrm{Vdc}$ and is dissipated by the resistor of the brake chopper. This happens in all four

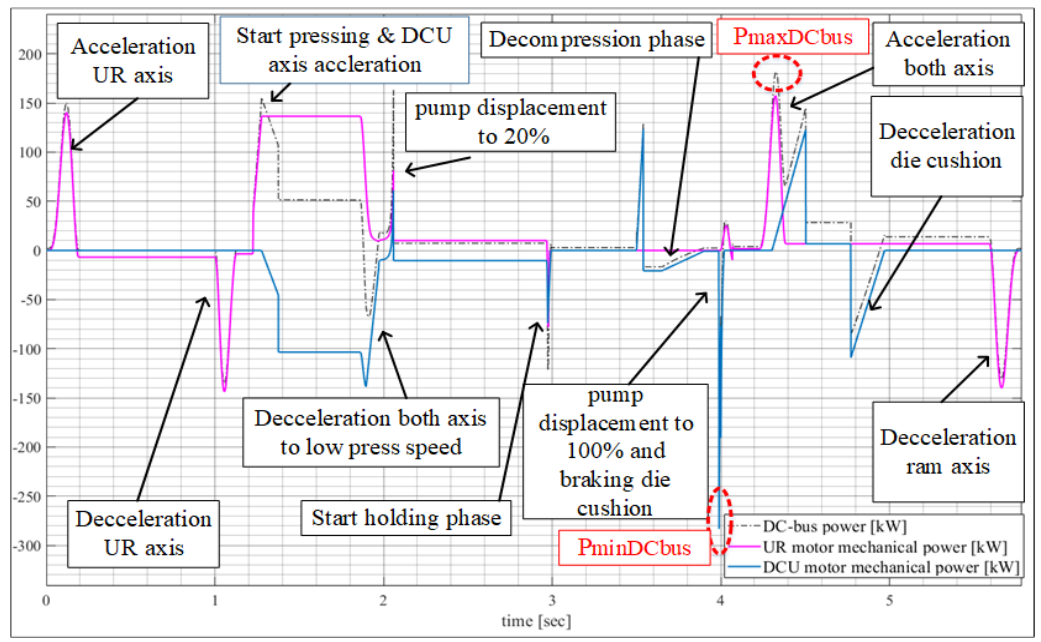

Figure 10: Power flow, process phases of the duty cycle 
deceleration phases of both axes (combined), as well as during the fluid decompression phase. Here, the compression energy is transformed to electrical energy trough a power flow over pump, motor and drive into the DC bus.

\subsection{Peak shaving}

Looking at the DC bus power flow over time, shown in Figure 10, we observe that the peak power demand in that specific forming cycle is $183 \mathrm{~kW}$ in the acceleration phase of the upward movement of the upper ram $(\mathrm{t}=4.3 \mathrm{sec})$. There are other power peaks of around $|100|$ to $|150|$ $\mathrm{kW}$ mostly during acceleration and deceleration of one or both axes. The average power of the cycle, however, is only around $13 \mathrm{~kW}$. This high ratio of maximum required power to average power already indicates that using a peak shaving approach is likely to lead to beneficial results. Indeed, the topologies from scenario A, $\mathrm{B}$ and $\mathrm{C}$ reduce the power infeed to:

$\frac{P_{\operatorname{maxIn}}}{P_{\operatorname{maxDCbus}}}=\frac{35 \mathrm{~kW}}{183 \mathrm{~kW}}=19 \%$

from the maximum occurring value $P_{\max D C b u s}$. Looking at the same ratio for the regenerative power, in the case of scenario $\mathrm{D}$, the savings are even more drastic with:

$\frac{P_{\operatorname{maxIn}}}{\left|P_{\operatorname{minDCbus}}\right|}=\frac{35 \mathrm{~kW}}{276 \mathrm{~kW}}=13 \%$

\subsection{Energy consumption and losses}

Figure 9 (upper right, lower right graph) shows the occurring losses of the different components for

scenario $\mathrm{C}$ over time. For a better overview, we calculated the average losses over the cycle as

$P_{\text {lavg }}=\frac{1}{\mathrm{~T}} \int_{0}^{T} P_{l}(t) d t$

for each component in each scenario and list the values in Table 5. Roughly, in scenario A to E, the share of losses is about one third for the pumps, one third for the drives, and the last third for the motors, infeed and capacitors. Unsurprisingly, the topology in scenario E with a brake resistor and no storage or feedback possibility has the highest energy intake. The most efficient topology is scenario $\mathrm{C}$, followed by scenario $\mathrm{A}$, then $\mathrm{D}, \mathrm{B}$, and $\mathrm{E}$.
Table 5: Average loss in [kW] for scenario A-E

\begin{tabular}{llllll}
\hline Scenario & A & B & C & D & E \\
& & & & & \\
\hline Pumps & 3.4 & 3.4 & 3.4 & 3.4 & 3.4 \\
Motors & 1.67 & 2.33 & 1.45 & 1.44 & 1.82 \\
Drives & 3.84 & 4.22 & 3.52 & 3.48 & 4.03 \\
Capacitors & 0.21 & 0.26 & 0.17 & 0 & 0 \\
Infeed & 0.43 & 0.56 & 0.86 & 1.42 & 1.69 \\
Chopper & 0 & 0 & 0 & 0 & 5.28 \\
\hline Total & $\mathbf{9 . 5 9}$ & $\mathbf{1 0 . 8 1}$ & $\mathbf{9 . 4 5}$ & $\mathbf{1 0 . 1}$ & $\mathbf{1 7 . 3}$ \\
\hline
\end{tabular}

Working with a higher DC bus voltage clearly leads to less drive and motor losses, just like the comparison of the $480 \mathrm{Vac}$ supply in scenario A and $400 \mathrm{Vac}$ in scenario B indicates. Since energy management topologies similar to scenario D were recently used for EAS-based machinery, we set the energy consumption of this scenario to $100 \%$ in Table 6. We split the comparison in two categories, with and without pump, each scenario's losses compared relatively to the ones from scenario D. For end users certainly the first value is of interest: how much energy is consumed less by the machine as a whole. When comparing energy management topologies on a broader basis, the second value might be the more meaningful one. The differences in energy consumption of scenarios A to D are all in all rather small. Due to potential model and parameter uncertainties a sharp judgment lower than a $10 \%$ level might not be justifiable. Nevertheless, the topology from scenario $\mathrm{A}$ and $\mathrm{C}$ are certainly in the same range in terms of energy consumption as the one in scenario $\mathrm{C}$, or slightly better. The solution with a lower operating voltage in scenario $\mathrm{B}$ is equal or slightly less efficient.

Table 6: Relative total loss, normalized to scenario D

\begin{tabular}{llllll}
\hline Scenario & A & B & C & D & E \\
\hline Loss [\%] with pump: & 95 & 107 & 93 & $\mathbf{1 0 0}$ & 171 \\
Loss [\%], no pump: & 92 & 111 & 90 & $\mathbf{1 0 0}$ & 208 \\
\hline
\end{tabular}

\subsection{Cost estimation}

A complete cost of ownership analysis requires a lot of details e.g. the exact cabinet design and lifetime and maintenance considerations of all components. This goes well beyond the scope of this first investigation. However, we provide a rough indication how the energy management topologies compete in terms of cost, since this is 
a crucial point in a technology's potential market acceptance.

In Table 7 we show the qualitative costs for all EMTs, with the EMT for scenario D set to $100 \%$. The topology in scenario E is clearly the most inexpensive solution with $50 \%$ to $60 \%$ compared to the active front end solution. All peak power limiting topologies from scenario A, $\mathrm{B}$ and $\mathrm{C}$ are cost competitive, they even seem to be slightly cheaper compared to scenario D. The energy storage in these EMTs roughly take one third of the total cost, but the infeed share becomes rather small with around $10 \%$. In scenario D around $60 \%$ of the costs are the large active front end supply and the LCL Filter.

Table 7: Qualitative cost comparison EMTs

\begin{tabular}{llllll}
\hline $\begin{array}{l}\text { Scenario } \\
\text { Component }\end{array}$ & $\mathrm{A}$ & $\mathrm{B}$ & $\mathrm{C}$ & $\mathrm{D}$ & $\mathrm{E}$ \\
\hline Infeed & 10 & 10 & 12 & 40 & 11 \\
$\begin{array}{l}\text { Filter \& Choke } \\
\text { Capacitors }\end{array}$ & 27 & 8 & 6 & 23 & 5 \\
$\begin{array}{l}\text { Chopper } \\
\text { Pre-charger }\end{array}$ & & & 47 & & \\
$\begin{array}{l}\text { Cabinet } \\
\text { Transformer }\end{array}$ & 38 & 38 & 38 & 32 & 32 \\
\hline Total & 96 & 86 & 88 & $\mathbf{1 0 0}$ & 59 \\
\hline
\end{tabular}

\section{CONCLUSION AND OUTLOOK}

In this paper, we modeled an electro hydrostatic drivetrain based forming press, powered by five different energy management topologies. The results indicate that a topology consisting of a supplying infeed and a well-sized amount of passive capacitors coupled into the DC-bus is a very suitable option. The installed power is significantly reduced to less than one fifth of the peak power. The differences between the scenarios $\mathrm{A}$ to $\mathrm{C}$ regarding the efficiency compared to scenario D are rather small. However, we certainly can state that the solutions from the scenario $\mathrm{A}, \mathrm{B}$ and $\mathrm{C}$ are in the same range of efficiency than scenario $D$. Through further verification of the models, especially the capacitor loss model, we want to refine the energy consumption analysis.

Looking at the costs, we made a rough estimation of all main components of each of the five energy management topologies. We found that the systems in scenarios $\mathrm{A}$ to $\mathrm{C}$ are at least equal, possibly even around $10 \%$ more cost effective than scenario D. All energy management topologies are competitive to scenario $\mathrm{E}$ - the most cost effective solution since the amortization periods to recover the large difference in losses are rather short. In this work we focused on a small machine and showed how much the peak power can be reduced at stable or even declining costs, without any trade off in power consumption. Looking at larger forming presses of several thousand tons and Megawatts of peak power, the detailed simulation and analysis of a satisfying and cost effective EMT becomes more important. The authors from [9] reduced the installed peak power on servo presses with the help of capacitors, above a certain press tonnage with an additional kinetic storage. Likewise, in [16], the author states that the use of kinetic storage becomes beneficial for servo presses larger than 600to. The author also claims, without further specifics, that the same peak shaving approach is valid for hydraulic presses. Where the "break evens" of different storage technologies are for EAS-based press systems - if they exist at all — is something that still needs to be investigated. In any case, the use of active storage, like DC-controlled capacitor units or the aforementioned servo flywheels add complexity and demand the presence of an advanced control strategy.

The approaches presented in this paper cover the energy management sophistication levels from one to three, as defined in section 1.1, and focus on a passive electrical storage. We showed that those solutions are competitive in terms of efficiency and costs. The integration of active storages into the topology leads to more degrees of freedom and possibilities of optimization. Inevitably, this will lead into a non-linear optimization problem with several degrees of freedom and competitive cost functions, e.g. efficiency versus maximum infeed current. Once this is well understood we further plan to penetrate energy sophistication level five where an online learning approach will identify suboptimality regarding the actual cost function(s) and adapt the control outputs in a way to further optimize the total performance over the cycle. Looking towards the (not that far off) future with machines having internet of things (IOT) interfaces, a smart energy management system can certainly play an interesting and important part. Machines might (a)synchronize their production cycle to others trough self- 
organization in the same factory or even in the same grid. Power could be drawn in and stored whenever low-priced, peak power could be fed back when advantageous for the common grid.

\section{NOMENCLATURE}

\begin{tabular}{|c|c|c|}
\hline$U_{d c}$ & DC bus voltage & {$[\mathrm{V}]$} \\
\hline$U_{\text {sup }}$ & AC-Supply voltage, $3 x$ phase & [Vrms] \\
\hline$I_{\text {sup }}$ & Supply current, rectified to DC & {$[\mathrm{Idc}]$} \\
\hline $\mathrm{T}_{\mathrm{fr}}$ & Friction torque pump & {$[\mathrm{Nm}]$} \\
\hline$\Delta p$ & Pressure difference & [bar] \\
\hline$n$ & Motor and pump velocity & {$[\mathrm{rpm}]$} \\
\hline$\alpha$ & Pump displacement factor & [ ] \\
\hline$v$ & Fluid viscosity & [cSt] \\
\hline$Q_{l}$ & Pump leakage flow & {$[1 / \mathrm{min}]$} \\
\hline$P_{l p}$ & Pump losses & {$[\mathrm{kW}]$} \\
\hline$P_{c u}$ & Motor copper losses & {$[\mathrm{kW}]$} \\
\hline$I_{m}$ & Total motor current & [Arms] \\
\hline$R_{s}$ & Motor phase resistance & {$[\Omega]$} \\
\hline$I_{q}$ & Torque building current & [Arms] \\
\hline$I_{d}$ & Flux weakening current & [Arms] \\
\hline$P_{f e}$ & Iron losses, motor & {$[\mathrm{kW}]$} \\
\hline$f_{1}$ & Loss factor & {$[\mathrm{kW} / \mathrm{rpm}]$} \\
\hline$f_{2}$ & Loss factor & {$\left[\mathrm{kW} / \mathrm{rpm}^{2}\right.$} \\
\hline$P_{l m o t}$ & Motor total loss & {$[\mathrm{kW}]$} \\
\hline$P_{l d r v}$ & Drive total loss & {$[\mathrm{kW}]$} \\
\hline$P_{l d r v 0}$ & Drive total loss at zero current & {$[\mathrm{kW}]$} \\
\hline$f_{3}$ & Loss factor & {$[\mathrm{V} / \sqrt{V}]$} \\
\hline$I_{d c}$ & Actual DC bus current & [A] \\
\hline$U_{\text {nom }}$ & Nominal DC voltage & [Udc] \\
\hline$P_{l d r v n}$ & Drive nominal loss & {$[\mathrm{kW}]$} \\
\hline$P_{\text {lafe } 0}$ & Idle state losses AFE & {$[\mathrm{kW}]$} \\
\hline$P_{\text {nafe }}$ & Nominal losses AFE & {$[\mathrm{kW}]$} \\
\hline$P_{l L C L}$ & Loss LCL Filter & {$[\mathrm{kW}]$} \\
\hline$P_{\text {idle }}$ & Drive loss at zero current & {$[\mathrm{kW}]$} \\
\hline$I_{\text {grid }}$ & Grid current $3 \times$ phase & [Arms] \\
\hline$I_{\text {nom }}$ & Nominal grid current $3 \mathrm{x}$ phase & [Arms] \\
\hline$P_{l a c d c}$ & Loss AC\DC\DC & {$[\mathrm{kW}]$} \\
\hline$P_{l a c d c 0}$ & Loss $A C \backslash D C \backslash D C$ at zero current & $\mathrm{t}[\mathrm{kW}]$ \\
\hline$P_{\text {nacdc }}$ & Nominal losses AC $\backslash D C \backslash D C$ & {$[\mathrm{~kW}]$} \\
\hline$I_{\text {ninf }}$ & Nominal current infeed & {$[\mathrm{kW}]$} \\
\hline$I_{n c h}$ & Nominal current choke & {$[\mathrm{kW}]$} \\
\hline$P_{n c h}$ & Nominal losses choke & {$[\mathrm{kW}]$} \\
\hline $\operatorname{ESR}(\omega)$ & Equivalent series resistance & {$[\Omega]$} \\
\hline $\tan \delta$ & Capacitor dissipation factor & [ ] \\
\hline$\omega$ & Current ripple frequency & {$[\mathrm{rad} / \mathrm{s}]$} \\
\hline$C$ & Electrical capacitance & {$[\mathrm{F}]$} \\
\hline$P_{l c p}$ & Capacitor loss & {$[\mathrm{kW}]$} \\
\hline$I_{\text {leak }}$ & Capacitor leakage current & [A] \\
\hline$A_{u r}$ & Area cylinder, upper ram & {$\left[\mathrm{cm}^{2}\right]$} \\
\hline$s_{u r}$ & Cylinder stroke, upper ram & {$[\mathrm{mm}]$} \\
\hline$m_{u r}$ & Die mass, upper ram & {$[\mathrm{kg}]$} \\
\hline$A_{d c}$ & Area cylinder, die cushion & {$\left[\mathrm{cm}^{2}\right]$} \\
\hline$s_{d c}$ & Cylinder stroke, die cushion & {$[\mathrm{mm}]$} \\
\hline$m_{d c}$ & Die mass, die cushion & {$[\mathrm{kg}]$} \\
\hline & Maximum incoming power & {$[\mathrm{kW}]$} \\
\hline
\end{tabular}

$\begin{array}{lll}P_{\text {maxDCbus }} & \text { Maximum DC bus power } & {[\mathrm{kW}]} \\ P_{\text {minDCbus }} & \text { Minimum DC bus power } & {[\mathrm{kW}]} \\ P_{\text {lavg }} & \text { Average losses } & {[\mathrm{kW}]} \\ P_{l} & \text { Generic losses } & {[\mathrm{kW}]}\end{array}$

\section{REFERENCES}

[1] Rüger H (2012) Energieeffiziente Hydraulikpressen durch Servodirektantrieb. In: 19. Sächsische Fachtagung Umformtechnik SFU Chemnitz, 13.-14. November 2012. Proceedings/Tagungsband 66, Verlag Wissenschaftliche Skripten, Chemnitz, S.365-378

[2] Lohse H, Weber J, Neumann S, Händle W, Klug D (2015) Investigation and improvement of the energy efficiency of hydraulic deep drawing presses. Presented at the 14th Scandinavian international conference on fluid power, Tampere, Finland, 20-22 Mai 2015

[3] Schenke C, Weber J (2018) Steigerung der Energieeffiziens, Verdrängersteuerung senkt den Energiebedarf hydraulischer Tiefziehpressen. O\&P Fluidtechnik 9/2018:54-59

[4] Willkomm J (2016) Modellprädiktive Optimierung drehzahlvariabler Verstellpumpen. Dissertation, Technische Universität Dresden

[5] Händle W, Kirch K (2017) Case Study Electro hydrostatic actuation system. Industrial $\quad-\quad$ Moog, Inc. https://www.moog.com/content/dam/moog/lit erature/ICD/Moog The Best of Both Worl ds.pdf Accessed 01 Oct 2019

[6] Siemer E, Kluge A. (2016) Ecoplant Design Moderne Antriebskonzepte für Schmiedepressen. O\&P Fluidtechnik 1112/2016:72-75

[7] Putz M, Blau P et al (2016) Energy storage in drive systems of servo presses for reduction of peak power and energy recovery. Paper presented at the Institute of Electrical and Electronics Engineers -IEEEE- EPE, ECCE Europe, $18^{\text {th }}$ European Conference on Power Electronics and Applications, Fraunhofer Institute for machine tools and forming technology, Karlsruhe, 5-9 September 2016

[8] Henning V, Garretson I et al (2018) Peak Power Load and Energy Costs Using the Example of the Startup and Idling of a Grinding Machine. Paper presented at the 
25th CIRP Life Cycle Engineering (LCE) Conference, Copenhagen, $30^{\text {th }}$ April $-2^{\text {nd }}$ May 2018

[9] Kaiser S, Kaever M, Budig P.-K, Ecorchard $\mathrm{G}$ et al (2011) Effizienz im Energiemanagement mit elektrischer Energiespeicherung in der Umformtechnik (E4U). In: Schlussbericht Verbundsprojekt http://publica.fraunhofer.de/documents/N203362.html 25 March 2019

[10] Ristic S, Wahler M (2018) Electrification of Hydraulics opens new ways for intelligent energy-optimized systems. In: 11th IFK Proceedings 2018 Vol 2

[11] Arnivouior L, Laurila, L (2007) Loss calculation of a frequency converter with a fixed-step circuit simulator. In: Proceedings of the European Power Electronics and Applications Conference 2007

[12] Moog Inc. (2018) Electrohydrostatic Pump Unit, Revision G, October 2018 https://www.moog.com/content/dam/moog/lit erature/ICD/Moog_Actuator EPU Catalog_e $\underline{\text { n.pdf }}$

Accessed 07 Mar 2019
[13] Moog Inc. (2017) Modular Multi-axis Servo Drive System MSD, Revision J, November 2017

https://www.moog.com/content/dam/moog/lit erature/ICD/Moog-ServoDrives-MSDSeriesCatalog-en.pdf Accessed 07 Mar 2019

[14] Hitachi Chemical Company Ltd. (2016) Screw terminal type aluminum electrolytic capacitors VFHR Series 161201 http://www.hitachichem.co.jp/english/products/sds/files/e vfhr 161201.pdf Accessed 07 Mar 2019

[15] Krishnan R (2010) Permanent magnet synchronous and brushless DC motor drives, Electrical and Computer Engineering Department Virginia Tech Blacksburg, Virginia, U.S.A.

[16] Dietz B, Reichl G (2018): Der Last die Spitze nehmen, Umformtechnik https://www.umformtechnik.net/fachartikel/d er-last-die-spitze-nehmen-\%7Cumformtechnik 34886 de/ Accessed 12 Nov 2019 